\title{
JOINING OF LOW-CARBON STEEL SHEETS WITH AI-BASED WELD
}

\begin{abstract}
The analysis of the connection steel/Al/steel made by resistance welding was performed. The used low-carbon steel had low content of carbon and other elements, aluminum was of 99.997 wt.\% Al purity. Formation of various FeAl intermetallic phases found in the phase diagram depending on the duration of the process was analyzed. Two distinctively different types of structure depending on time of welding were observed: 1) hypoeutectic structure for samples processed for $5 \mathrm{~s}$, and 2) eutectic structure for samples processed for $10 \mathrm{~s}$ and more. The shear test showed increase of mechanical properties of the connection for the samples welded $10 \mathrm{~s}$.
\end{abstract}

Keywords: resistance welding, $\mathrm{Al} / \mathrm{Fe}$ interface, shear test

\section{Introduction}

There are many methods for joining steel elements. The most popular include acetylene or oxy-acetylene welding and metal arc welding. The main disadvantage of the mentioned methods is necessity of partial melting of the material being connected. In some cases, soldering or adhesive bonding may be applied. The latter, however, does not penetrate into structure of material, and is characterized by limited strength, low thermal stability and it requires good wettability of the joined pieces of material. An alternative for the discussed methods is resistance welding when a connection based on intermetallic phases is formed due to strong reaction of a weld with the material being joined. The characteristic feature of such joint is profound growth of the intermetallic phases into the structure [1]. The physical analysis of the processes occurring during the resistance welding shows that the most advantageous is such a choice of components, so the resulting reaction has endothermic nature. Such situation is favorable in respect of energy necessary for the process of connection formation and width of interface. An increase of the width of the interface rich in the intermetallic phases allows for continuous transition from a metal structure into a nugget. It will also prevent formation of a notch-like effects at the interface and, as a consequence, brittle connection.

A sequence of formation of phases in a connection can be also described thermodynamically. In case of both, stable and metastable crystallization types, the theoretical models have been elaborated [2]. The sequence of formation of phases in case of $\mathrm{Ni} / \mathrm{Al} / \mathrm{Ni}$ connection with special attention paid to crystallization associated with peritectic reactions is described in [2]. Studies have shown that this kind of processes usually involve stable crystallization which almost immediately changes into metastable one, which favors the joint formation
[3]. Results of the similar studies performed in case of aluminum coating on iron substrate are presented in [4,5]. On the other hand, taking example of $\mathrm{Ni} / \mathrm{Al} / \mathrm{Ni}$ system, Wolczynski et al. [6] proposed that formation of each connection can be justified by use of phase diagram and calculation of driving force of the formation of intermetallic phases.

Aluminum was chosen as a most promising metal for welding of steel sheets. The $\mathrm{Fe}-\mathrm{Al}$ phase diagram indicate possibility of formation of large variety of stable intermetallic phases such as: $\mathrm{Fe}_{3} \mathrm{Al}, \mathrm{Fe}_{2} \mathrm{~A}_{15}, \mathrm{FeAl}, \mathrm{FeA}_{12}, \mathrm{FeA}_{13}$ and additionally $\varepsilon$ phase $\mathrm{Fe}_{4} \mathrm{~A}_{15}$ [7]. Temizel et al. observed formation of these phases and also $\mathrm{Fe}_{2} \mathrm{~A}_{13}$ on low-carbon steel coated with $\mathrm{Al}$ layer 2 to $14 \mu \mathrm{m}$ thick with respect to temperature and time [8]. However some data available in the literature on the production of aluminum coatings on steels report that not all phases must form at certain conditions [9-12]. Also, the interface between individual phases turns out to be irregular towards both steel and aluminum $[1,12,13]$. Moreover, the reaction aluminumiron is strongly endothermic. Thus, energetic aspect of the reaction is difficult to control during welding process.

\section{Experimental methods}

The studies were conducted on low carbon $(0.4$ wt.\% C) steel with low content of other elements. Aluminum strip of purity 99.997 wt. \% Al was used as a weld. The pieces with width of $10 \mathrm{~mm}$ and length of $50 \mathrm{~mm}$ were cut off the steel sheets with thickness of $1.5 \mathrm{~mm}$. The sheet with relatively high thickness shows higher stiffness of the joined samples during tension and causes pure shear stresses. The longer side of the samples was parallel to the rolling direction. The pieces of steel of the same thickness were always chosen and a piece of aluminum strip was inserted in between to form a sandwichlike sample to be welded.

\footnotetext{
* AGH UNIVERSITY OF SCIENCE AND TECHNOLOGY, FACULTY OF NON-FERROUS METALS, AL. MICKIEWICZA 30, 30-065 KRAKOW, POLAND

\# Corresponding author: mperek@agh.edu.pl
} 
The procedure of joining of the metallic samples is presented in Figure 1. The samples were resistance welded at the device of own design as it is shown in Figure 2. The graphite electrodes were the operating elements that were attached to a springy holder that ensured constant welding force. Repeatable welding conditions were possible due to control of current characteristics of the process. Direct measurement of temperature by means of thermocouple was impossible due to high dynamics of temperature changes, especially during transition of aluminum weld into liquid state.

Samples, as shown in Figure 1, were placed in between the graphite electrodes. Argon atmosphere was introduced into the chamber, and the current flowed through the samples being welded. The amount of current was increased continuously from 0 up to maximal value of $120 \mathrm{~A}$. After melting of a solder, a rapid increase of current up to about 140 A took place, due to sudden change of electric properties during solid-to-liquid phase transformation and formation of a layer of intermetallic phases at the $\mathrm{Fe} / \mathrm{Al} / \mathrm{Fe}$ interfaces. Time of welding was 5 to 15 seconds. The sides of the obtained samples were cut off at the electric erosion cutting device in order to get rid of possible inhomogeneities of the joint at the edges of a sample and keep reproducible geometry of the samples. a)

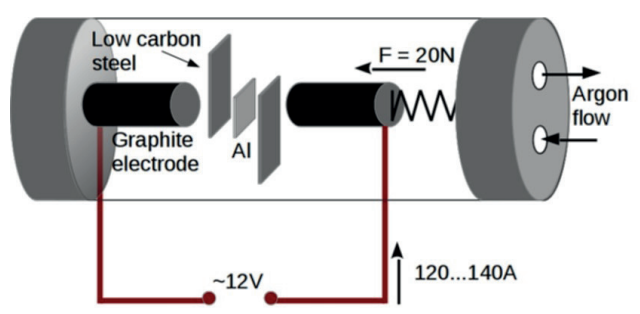

b)

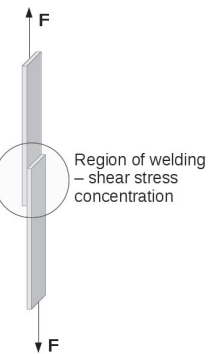

Fig.1. Schematic view of a) the device used for resistance welding; $b$ ) samples being connected

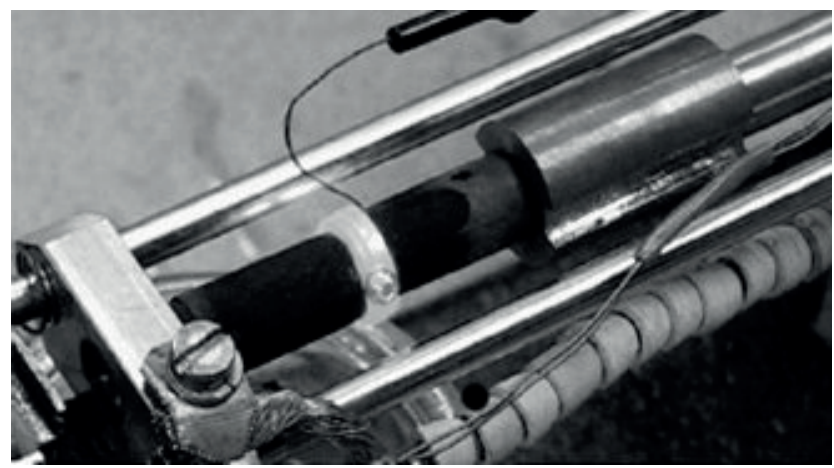

Fig.2. Actual view of device used for resistance welding without a glass tube used for introduction of argon.

Next, all the samples underwent shear test at ambient temperature. The type of connection, in this case, a grooved joint determined the stresses during tensile test had shearing character. During the deformation test, shearing path and force were registered. The stress achieved in the test was determined in two ways: 1) the initial area of the joint (theoretical) or 2) a correction regarding change of area during the process of shearing (true) were taken into calculations. Both results are showed in the diagrams (Fig.3).
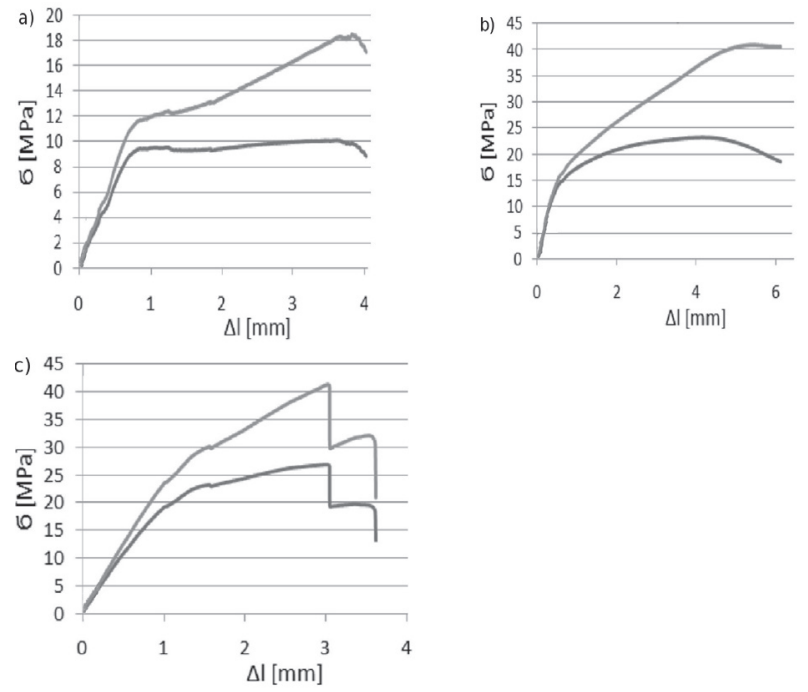

Fig.3. Characteristics of shear test of samples welded for a) $5 \mathrm{~s}, \mathrm{~b}$ ) $10 \mathrm{~s}$ and c) $15 \mathrm{~s}$.

Some of the samples were destined for structural analysis at scanning electron microscope (SEM). The studies were performed at SEM Hitachi S-3400N with tungsten electron gun. The samples were polished at emery papers up to 2000, then polished at cloth with diamond paste of $1 \mu \mathrm{m}$, followed by final polishing with use of colloidal silica. The lateral cross-section, shape of the connection (including thickness) were observed. Besides, analysis of the phases formed at the interface was conducted by means of Thermo energy dispersive spectroscopy (EDS) at accelerating voltage of $20 \mathrm{kV}$.

\section{Discussion and results}

\subsection{Mechanical properties}

The results of shear test of samples welded with aluminum are presented in Figure 3. It was found that strength of the connection increases from 10 to $25 \mathrm{MPa}$ with time of welding of 5 to $15 \mathrm{~s}$, respectively. The best mechanical properties exhibit samples after $10 \mathrm{~s}$ of welding. Samples after $5 \mathrm{~s}$ of welding showed good plasticity at low mechanical properties. The samples welded for $15 \mathrm{~s}$ showed similar strength as samples welded for $10 \mathrm{~s}$ but showed much lower plasticity. The cause of such behavior explained microstructural studies.

\subsection{Structural analysis}

In order to decide on the influence of microstructure on the obtained results, the SEM analyses were performed. The samples welded with aluminum show highly developed interface made of intermetallic phases (Fig.4). The amount of the created phases increases with the welding time. The hypoeutectic structure of the joint formed only after $5 \mathrm{~s}$ is presented in Figure 4a. Next, after $10 \mathrm{~s}$, the structure changes drastically due to formation of intermetallic crystals growing towards center of the connection (Fig.4b). The structure formed after $15 \mathrm{~s}$ of welding contains blocks of intermetallic phase in the whole volume of the joint (Fig.4c). The block particles 

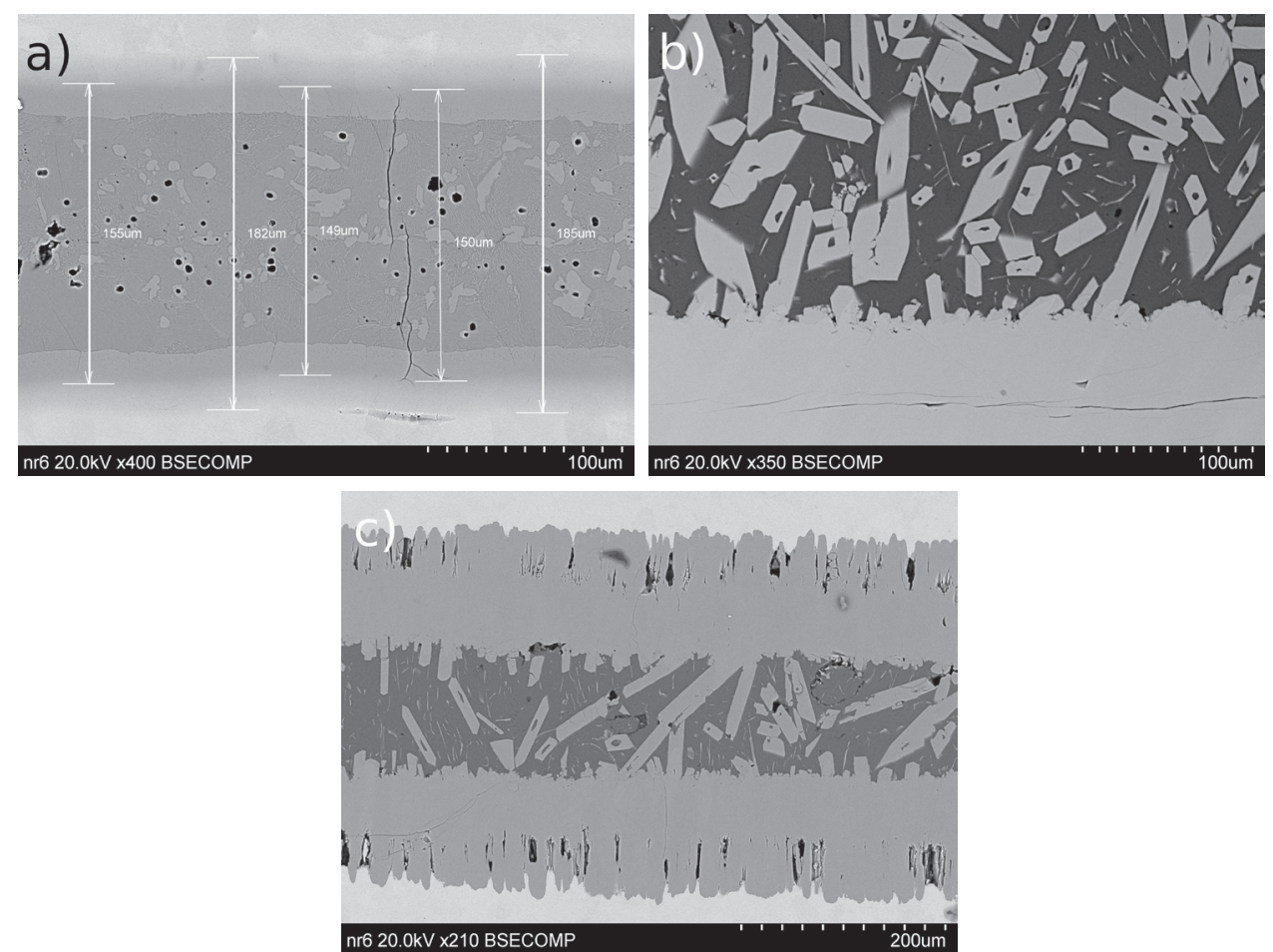

Fig.4. Scanning electron micrograph of a typical connections of samples resistance-welded for a) $5 \mathrm{~s}, \mathrm{~b}) 10 \mathrm{~s}$, c) $15 \mathrm{~s}$; electron backscattered images.

are formed as a result of primary crystallization directly from liquid.

Due to additional heat produced during exothermic reaction diffusion distance is much larger than it may be expected from the duration and temperature of the resistance welding process. Another characteristic feature is significant non-uniformity of the weld thickness due to resistance-welding technique itself associated with production of heat during reaction. With such short times of welding as discussed here, the diffusion process is limited mainly to heat channels. Dynamics of process on the border solid state/liquid prevents to equalize chemical composition by diffusion in the region of the connection.

As it is presented in Figure 4a and 5 (together with EDS analysis given in Table 1), in hypoeutectic state few distinctly different layers exist, which correspond to the following phases $\mathrm{Fe}, \mathrm{Fe}_{2} \mathrm{Al}_{5}, \mathrm{FeAl}, \mathrm{Fe}_{2} \mathrm{Al}_{3}$ and $\mathrm{FeAl}_{2}$, as it was determined by EDS technique. Besides, in the samples welded in short times, total consumption of Al with voids creation in the middle (due to Kirkendall effect) is noticed (Fig.5).

In longer times of the welding process, the $\mathrm{Fe}_{2} \mathrm{Al}_{5}$ phase is found at the interface close to original steel, while the intermetallic phase $\mathrm{Fe}_{3} \mathrm{Al}$ begins to grow from the interface towards the eutectic phase (aluminum with needle like precipitates of $\mathrm{Al}_{3} \mathrm{Fe}$ phase) as it is shown in Figures 6,7 and 8 (for chemical composition see Tables 2 and 3). Then the block-like precipitates grow within the vicinity of the 'cleared' aluminum phase. It is interesting to note, that the $\mathrm{Fe}_{3} \mathrm{Al}$ growing from the interface may connect with the same phase growing from the opposite side, and may lead finally to form a nugget made completely of $\mathrm{Fe}_{3} \mathrm{Al}$ phase. It was observed that $\mathrm{Fe}_{2} \mathrm{Al}_{5}$ phase has tongue-like shape of the front while $\mathrm{Fe}_{3} \mathrm{Al}$ grows as rods (Fig. 4b). Similar particles were observed in hypereutectic $\mathrm{Zn}$-Ti alloys [14,15].

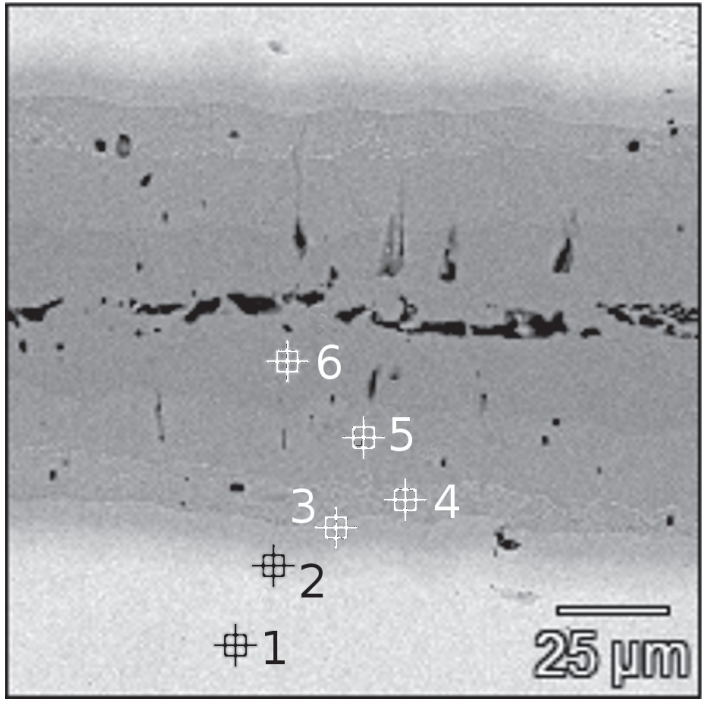

Fig.5. Scanning electron micrograph of a connections of samples welded for $5 \mathrm{~s}$. The marked points indicate places where EDS analysis was performed. The atomic concentration at these point is given in Table 1 .

TABLE 1

Atomic concentration of elements at points marked in Fig.5

\begin{tabular}{|c|c|c|c|}
\hline $\begin{array}{c}\text { No. of } \\
\text { analyzed point }\end{array}$ & $\mathrm{Al}$ & $\mathrm{Fe}$ & $\begin{array}{c}\text { Proposed intermetallic } \\
\text { phase }\end{array}$ \\
\hline 1 & & 100.00 & $\mathrm{Fe}$ \\
\hline 2 & 28.75 & 71.25 & $\mathrm{Fe}_{2} \mathrm{Al}_{5}$ \\
\hline 3 & 50.96 & 49.03 & $\mathrm{FeAl}$ \\
\hline 4 & 60.65 & 39.35 & $\mathrm{Fe}_{2} \mathrm{Al}_{3}$ \\
\hline 5 & 65.68 & 34.32 & $\mathrm{FeAl}_{2}$ \\
\hline 6 & 68.83 & 31.17 & $\mathrm{FeAl}_{2}$ \\
\hline
\end{tabular}




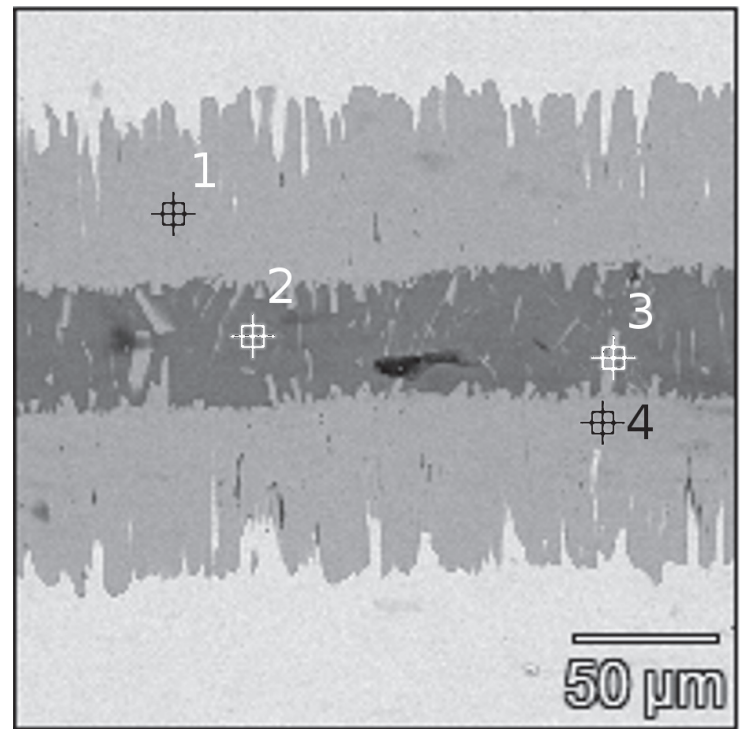

Fig.6. Scanning electron micrograph of a connection of a sample welded for $10 \mathrm{~s}$. Tongue-like structures of $\mathrm{Fe}_{2} \mathrm{Al}_{5}$ and rods of $\mathrm{FeAl}_{3}$ intermetallic phases clearly visible.

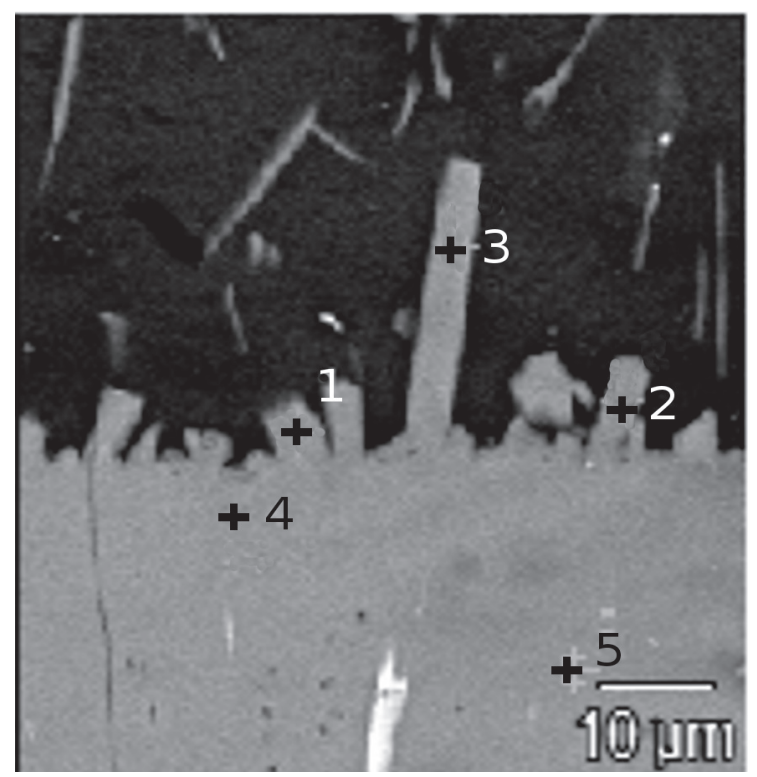

Fig.7. Scanning electron micrograph of a connections of samples welded for $10 \mathrm{~s}$. The marked points indicate places where EDS analysis was performed. The atomic concentration at these point is given in Table 2.

TABLE 2

Atomic concentration of elements at points marked in Fig. 5 proving formation of only two distinctive phases: $\mathrm{FeAl}_{3}$ and $\mathrm{Fe}_{2} \mathrm{Al}_{5}$.

\begin{tabular}{|c|c|c|c|}
\hline \hline $\begin{array}{c}\text { No. of } \\
\text { analyzed point }\end{array}$ & $\mathrm{Al}$ & $\mathrm{Fe}$ & $\begin{array}{c}\text { Proposed } \\
\text { intermetallic } \\
\text { phase }\end{array}$ \\
\hline 1 & 78.13 & 21.87 & $\mathrm{FeA}_{13}$ \\
\hline 2 & 79.23 & 20.77 & $\mathrm{FeA}_{13}$ \\
\hline 3 & 77.64 & 22.36 & $\mathrm{FeA}_{13}$ \\
\hline 4 & 73.71 & 26.29 & $\mathrm{Fe}_{2} \mathrm{~A}_{15}$ \\
\hline 5 & 73.72 & 26.28 & $\mathrm{Fe}_{2} \mathrm{~A}_{15}$ \\
\hline
\end{tabular}

Fig.8. Scanning electron micrograph of a connections of samples welded for $10 \mathrm{~s}$. The marked points indicate places where EDS analysis was performed. The atomic concentration at these point is given in Table 3.

TABLE 3

Atomic concentration of elements at points marked in Fig.5 proving formation of only two distinctive phases: $\mathrm{FeAl}_{3}$ and $\mathrm{Fe}_{2} \mathrm{Al}_{5}$

\begin{tabular}{|c|c|c|c|}
\hline \hline $\begin{array}{c}\text { No. of } \\
\text { analyzed point }\end{array}$ & $\mathrm{Al}$ & $\mathrm{Fe}$ & $\begin{array}{c}\text { Proposed intermetallic } \\
\text { phase }\end{array}$ \\
\hline 1 & 72.11 & 27.89 & $\mathrm{Fe}_{2} \mathrm{Al}_{5}$ \\
\hline 2 & 99.52 & 0.48 & $\mathrm{Al}$ \\
\hline 3 & 78.50 & 21.50 & $\mathrm{FeAl}_{3}$ \\
\hline 4 & 73.50 & 26.50 & $\mathrm{Fe}_{2} \mathrm{Al}_{5}$ \\
\hline
\end{tabular}

\section{Summary}

It was observed that duration of the resistance welding significantly influences diffusion of $\mathrm{Fe}$ and $\mathrm{Al}$, and thus, the structure of the joint. In the Fe-Al system, eutectic appear at 0.03 at.\% Fe. During welding, due to reaction of molten aluminum with iron, an intensive dissolution of iron and its migration into aluminum takes place. An important factor here is duration of reaction. Short thermal exposure during welding for $5 \mathrm{~s}$ causes development of hypoeutectic solution of iron in aluminum, due to which crystallization of grains of $\alpha$ phase followed by precipitation of eutectic phases. Increase of welding time results in increase of iron content in molten aluminum to a hypereutectic level. Thus, primary crystallization of intermetallic phase directly from the liquid is possible, what causes large size of the particles. Short times of welding process $(5 \mathrm{~s})$ results in multi-phase structure of the nugget (composed of $\mathrm{Fe}, \mathrm{Fe}_{2} \mathrm{Al}_{5}, \mathrm{FeAl}, \mathrm{Fe}_{2} \mathrm{Al}_{3}$ and $\mathrm{FeAl}_{2}$ ) and low shear strength. After 10 or $15 \mathrm{~s}$ of welding, only two intermetallic phases dominate the structure: $\mathrm{Fe}_{2} \mathrm{Al}_{5}$ and $\mathrm{Fe}_{3} \mathrm{Al}$ phases. The optimal structural and mechanical properties of the weld were achieved after $10 \mathrm{~s}$ of the process. 


\section{Acknowledgment}

The financial support of the State Committee for Scientific Research of Poland under the grant number 11.11.180.653 is kindly acknowledged.

\section{REFERENCES}

[1] R. Qiu, H. Shi, K. Zhang, Y. Tu, C. Iwamoto, S. Satonaka, Interfacial characterization of joint between mild steel and aluminum alloy welded by resistance spot welding, Materials Characterization 61 684-688 (2010).

[2] W. Wołczyński, J. Janczak-Rusch, J. Kloch, T. Rutti, T. Okane A Model for Solidification of Intermetallic Phases from Ni-Al System and its Application to Diffusion Soldering, Archives of Metallurgy and Materials 50, 1055-1068 (2005)

[3] W. Wołczyński Transition Phenomena in the Diffusion Soldering / Brazing, Archives of Metallurgy and Materials 51, 609- 615 (2006).

[4] C. Senderowski, A. Pawłowski, Z. Bojar, W. Wołczyński, M. Faryna, J. Morgiel, Ł. Major, TEM Microstructure of Fe-Al Coatings Detonation Sprayed onto Steel Substrate, Archives of Metallurgy and Materials 55, 373-381 (2010).

[5] A. Pawłowski, C. Senderowski, W. Wołczyński, J. Morgiel, Ł. Major, Detonation Deposited Fe-Al Coatings Part II: Transmission Electron Microscopy of Inter-layers and Fe-Al Intermetallic Coating Detonation Sprayed onto the 045 Steel Substrate, Archives of Metallurgy and Materials 56, 71-79 (2011).

[6] W. Wołczyński, T. Okane, C. Senderowski, D. Zasada, B. Kania, J. Janczak-Rusch, Thermodynamic Justification for the $\mathrm{Ni} / \mathrm{Al} / \mathrm{Ni}$ Joint Formation by a Diffusion Brazing, International Journal of Applied Thermodynamics 14, 97-105 (2011).

[7] T. B. Massalski, Editor-in-Chief; H. Okamoto, P.R. Subramanian, L. Kacprzak, Binary alloy phase diagrams ASM International, Materials Park, Ohio, USA, (1990).

[8] G. Temizel, M. Özenbas, Intermetallic Phase Formation at Fe-Al Film Interfaces, Turkish Journal of Engineering \& Environmental Sciences 31, 71-78 (2007).

[9] S. Kobayashi, T. Yakou, Control of intermetallic compound layers at interface between steel and aluminium by diffusiontreatment, Materials Science and Engineering A 338, 44-53 (2002).

[10] D. Naoi, M. Kajihara, Growth behavior of $\mathrm{Fe}_{2} \mathrm{Al}_{5}$ during reactive diffusion between $\mathrm{Fe}$ and $\mathrm{Al}$ at solid-state temperatures, Materials Science and Engineering A 459 375-382 (2007).

[11] T.-S. Shih, S.-H. Tu, Interaction of steel with pure Al, Al-7Si and A356 alloys, Materials Science and Engineering A A454455, 349-356 (2007).

[12] K. Bouché, F. Barbier, A. Coulet, Intermetallic layer growth between solid iron and molten aluminium materials Science and Engineering A A249, 167-175 (1998).

[13] A. Bouayad, Ch. Gerometta, A. Belkebir, A. Ambari, Kinetic interactions between solid iron and molten aluminium, Materials Science and Engineering A A363, 53-61 (2003).

[14] G. Boczkal, Second phase morphology in the $\mathrm{Zn}-\mathrm{Ti} 0.1-\mathrm{Cu} 0.1$ single crystals obtained at different growth rates, Archives of Metallurgy and Materials 57, 479-484 (2012).

[15] G. Boczkal, Structure and properties of $\mathrm{Zn}-\mathrm{Ti} 0.2-\mathrm{Cu} 0.15$ single crystal containing eutectic precipitates, Archives of Metallurgy and Materials 58, 1019-1022 (2013). 
